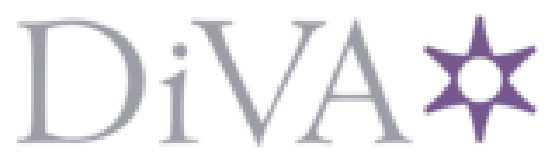

http://www.diva-portal.org

This is the published version of a paper published in Scandinavian Journal of Caring Sciences.

Citation for the original published paper (version of record):

Gabrielsson-Järhult, F., Nilsen, P. (2016)

On the threshold: older people's concerns about needs after discharge from hospital.

Scandinavian Journal of Caring Sciences, 30(1): 135-144

http://dx.doi.org/10.1111/scs.12231

Access to the published version may require subscription.

N.B. When citing this work, cite the original published paper.

Free Editor's Choice article

Permanent link to this version:

http://urn.kb.se/resolve?urn=urn:nbn:se:hj:diva-27089 


\title{
On the threshold: older people's concerns about needs after discharge from hospital
}

\author{
Felicia Gabrielsson-Järhult Reg. PT, PhD Student (Reg. Physioterapist) ${ }^{1}$ and Per Nilsen PN, MSc, PhD (Professor) ${ }^{2}$ \\ ${ }^{1}$ Institute of Gerontology, School of Health Sciences, Jönköping University, Jönköping, Sweden and ${ }^{2}$ Division of Community Medicine, \\ Department of Medical and Health Sciences, Linköping University, Linköping, Sweden
}

Scand J Caring Sci; 2016; 30; 135-144

\section{On the threshold: older people's concerns about needs after discharge from hospital}

Discharge from hospital is often strenuous for older people and requires adjustments from living an independent life to being in need of care and support. This study aims to explore older people's concerns about their needs after discharge. Twenty-seven observations recorded at hospital discharge planning meetings were analysed with content analysis. An overarching theme emerged: being in a life transition, which reflected the older person's vulnerable and ambiguous situation in the discharge process. The theme was developed from three categories: obtaining a secure life situation, need of continuous care and support, and influencing and regaining independence. The findings highlight that older patients want to influence their care after discharge. They strive to regain independence and express their concerns about how to obtain a secure life situation through care organised to fit their individual needs. Knowledge about older people's concerns is important for healthcare providers and social workers involved in planning and individualised care and services.

Keywords: care pathways, clinical decision-making, communication, discharge planning, elder care, patient participation.

Submitted 21 October 2014, Accepted 25 February 2015

\section{Introduction}

On discharge from hospital, the patient either returns home or is transferred to another facility such as a nursing home or a rehabilitation unit. Discharge planning is a process whereby patients' needs are assessed, resources to meet those needs are identified and plans are made to facilitate continuity of care from one environment to another $(1,2)$. For older people who have been hospitalised, the discharge process can be very difficult. Adjustment from living an independent life to be in need of care and support tends to be strenuous (3-6). Becoming dependent on formal care or informal care from family can challenge a person's sense of identity, autonomy and integrity (3).

Many factors make discharge planning especially difficult for older people. Older people may be frail due to disease and comorbidity, which makes it harder for them to exercise their right to influence the decisions made in the discharge planning process and argue for their needs for care $(4,7,8)$. Older people often experience

\section{Correspondence to:}

Felicia Gabrielsson-Järhult, Institute of Gerontology, School of

Health Sciences, Jönköping University, Box 1026, 51111

Jönköping, Sweden.

E-mail: gafe@hhj.hj.se difficulties in influencing critical decisions concerning the quality and continuity of their care $(9,10)$. Their wishes concerning care tend to clash with healthcare professionals' intentions and procedures $(11,12)$.

\section{Background}

The research literature from the early 1990s illustrates that discharge of older people from hospital has been of concern to healthcare professionals for a number of years (13). A consistent finding stressed in studies on the discharge planning process is patient dissatisfaction with the information received, which often results in increased anxiety for older people and their carers. Uncertainty associated with postdischarge care and everyday life can cause a great deal of emotional distress for the older person and their family $(5,11,14-16)$.

Research on discharge planning has examined this process using quantitative methods, typically using reductions in hospital length of stay and/or hospital readmissions as measures of the effectiveness of the process (17-19). However, numerous researchers (11, 13, 20-23) have called for studies that address discharge planning from the perspective of the older person and studies that involve the perspectives of both the patient and the carers. Some aspects of discharge planning meetings have been studied from the viewpoint of the older 
person, including their interaction with healthcare professionals $(16,24)$ and their perception of the information provided to them $(5,25)$. However, only a few of these studies are done in Sweden $(26,27)$. Research is also limited on older people's concerns about their postdischarge needs in discharge planning meetings. Knowledge about the older people's concerns is potentially of great importance for social workers and healthcare professionals to plan and optimise individualised care and services.

\section{Aim}

The aim of this study was to explore older people's concerns about their needs as expressed in discharge planning meetings at a hospital. Gaining a greater understanding of older people's concerns in this context can provide insights into how these meetings and postdischarge care may be improved, which is important for the well-being of older people and efficient service use.

\section{Methods}

\section{Design}

An explorative design based on observations was used in this qualitative study. Data from discharge planning meetings for 27 older patients were analysed using content analysis.

\section{Study setting}

This study took place at a county hospital in Sweden. Public health care in Sweden is universal, with fees regulated by law. The responsibility for older people's care in Sweden is separated into two levels. The government steers through economic incentives and legislation. Twenty-one county councils are responsible for providing health care and 290 municipalities provide social services, housing and institutional care for older people, according to their assessed needs. Ageing in place is an important principle in Sweden, enabling older people to live independently and manage with informal and formal care for as long as possible (28-30).

\section{Study participants}

Patients were selected strategically from information reported by staff about patients planned to be discharged during the next few days. Patients were contacted by first author (FGJ) at their hospital ward so they could give their informed consent (see Ethical considerations). Patients eligible for inclusion were 65 years or older, in Sweden 65 years is the common retirement age and lower limit for public old-age care. The patient should also be able to speak and read Swedish. Men and women of different age and different reasons for hospitalisation were included, representing a variety of medical diagnoses and medical and social histories. The study group included patients with and without previous experience of discharge meetings; patients with and without previous experience of healthcare use and Home help; patients who planned to bring their next of kin to the discharge planning meeting; and patients who did not. This approach was used in order to obtain informationrich and illustrative cases with varying medical conditions and experiences (31). We stopped inviting participants when a satisfactory variation of conditions and previous experience was reached. We did not approach patients diagnosed with dementia, under palliative care or those with severe loss of hearing.

Twenty-seven older patients were included in the study (17 women and 10 men, median age 81 years). They were cared for at five different hospital units: geriatric, orthopaedic, infection, medical and surgical. Demographic data, medical information and previous experience of care and discharge planning were obtained from the patients' medical records (Table 1).

Twenty-five next of kin and 19 healthcare professionals participated in the discharge planning meetings. The professionals were nurses, occupational therapists representing primary care or the hospital, and social workers employed by the local municipality. Some of them participated in more than one meeting.

\section{Data collection}

Data were collected through observations made by the first author by recording the discharge planning meetings using video and audio equipment. The meetings were carried out in the patients' ward room or in a meeting room close to the hospital ward.

The average duration of a discharge meeting was approximately 30 minutes (range, 15-45 minutes). The first author was present at all meetings as a passive observer supervising the recording and taking field notes. All but one of the discharge meetings were recorded, 22 with video- and audio tape recording, four only audio taped and one participant declined any recording. In total, 13 hours of video and audio were recorded.

\section{Data analysis}

Data were analysed using qualitative content analysis in accordance with Graneheim and Lundman (32) using both a manifest and a latent (interpretive) approach. Content analysis is a technique for analysing texts based on empirical data with an explorative and descriptive character. It entails a structured analysis process to code and categorise the data $(32,33)$. The first step involved verbatim 
Table 1 Characteristics of the older participants and their discharge planning meetings (DPM)

\begin{tabular}{|c|c|c|c|c|c|c|c|c|c|}
\hline Participant & Sex & $\begin{array}{l}\text { Age } \\
\text { years }^{a}\end{array}$ & Reason for hospital admission & $\begin{array}{l}\text { Days at } \\
\text { hospital }^{b}\end{array}$ & $\begin{array}{l}\text { Previous } \\
\text { experience } \\
\text { of care }\end{array}$ & $\begin{array}{l}\text { Previous } \\
\text { experience } \\
\text { of DPM }\end{array}$ & $\begin{array}{l}\text { Social status and } \\
\text { living conditions }{ }^{c}\end{array}$ & $\begin{array}{l}\text { Next of kin } \\
\text { participating } \\
\text { in DPM }\end{array}$ & $\begin{array}{l}\text { Professionals } \\
\text { Participating } \\
\text { in DPM }\end{array}$ \\
\hline P1 & M & 84 & Infection diabetes confusion & 10 & No & No & W/A & 2 & NA, DN \\
\hline P2 & M & 84 & Car accident wounds & 8 & No & No & W/A & 0 & NA, DN, OT \\
\hline P3 & M & 93 & Chest pain dizziness & 13 & Yes & Yes & W/A & 0 & NA, OT \\
\hline P4 & M & 90 & Wound infection & 5 & Yes & Yes & $\mathrm{M} / \mathrm{T}$ & 1 & NA, DN \\
\hline P5 & M & 75 & Infection sepsis & 9 & No & No & $\mathrm{M} / \mathrm{T}$ & 2 & NA, OT \\
\hline P6 & $\mathrm{F}$ & 91 & $\begin{array}{l}\text { Stomach problem } \\
\text { unconscious }\end{array}$ & 12 & Yes & Yes & W/A & 0 & NA \\
\hline P7 & $\mathrm{F}$ & 73 & Unconscious stroke? & 8 & Yes & Yes & $\mathrm{M} / \mathrm{T}$ & 1 & NA \\
\hline P8 & $\mathrm{F}$ & 74 & Fractured thigh bone & 11 & Yes & No & $\mathrm{M} / \mathrm{T}$ & 0 & NA, OT \\
\hline P9 & $\mathrm{F}$ & 71 & Fractured bilateral upper arm & 9 & No & No & $\mathrm{M} / \mathrm{T}$ & 2 & NA, OT \\
\hline P10 & $\mathrm{F}$ & 88 & $\begin{array}{l}\text { Transient ischaemic attack? } \\
\text { Confusion }\end{array}$ & 13 & Yes & Yes & S/A & 1 & NA, WN \\
\hline P11 & $\mathrm{F}$ & 85 & Hip-joint operation & 11 & No & No & $\mathrm{M} / \mathrm{T}$ & 1 & NA, OT \\
\hline P12 & $\mathrm{F}$ & 74 & Fall, blood malignant disease & 11 & Yes & Yes & $\mathrm{S} / \mathrm{T}$ & 1 & NA, OT \\
\hline P13 & $\mathrm{F}$ & 72 & $\begin{array}{l}\text { Fracture upper arm, } \\
\text { gynaecological } \\
\text { malignancy }\end{array}$ & 25 & No & No & W/A & 1 & NA, OT \\
\hline P14 & $\mathrm{F}$ & 69 & $\begin{array}{l}\text { Fractured thigh bone } \\
\text { heart disease }\end{array}$ & 19 & No & No & S/A & 0 & NA \\
\hline P15 & $\mathrm{F}$ & 84 & $\begin{array}{l}\text { Breathing- and heart } \\
\text { problems }\end{array}$ & 25 & Yes & Yes & W/A & 2 & NA, DN \\
\hline P16 & M & 90 & $\begin{array}{l}\text { Fall, transient ischaemic } \\
\text { attack? }\end{array}$ & 9 & No & No & $\mathrm{M} / \mathrm{T}$ & 1 & NA \\
\hline P17 & $\mathrm{F}$ & 90 & Pneumonia & 12 & Yes & Yes & $\mathrm{S} / \mathrm{T}$ & 1 & NA \\
\hline P18 & M & 70 & Back pain assessment & 28 & Yes & Yes & W/A & 0 & NA, DN \\
\hline P19 & $\mathrm{F}$ & 79 & COL pneumonia & 13 & Yes & Yes & W/A & 0 & NA, DN \\
\hline P20 & $\mathrm{F}$ & 67 & Chest pain & 5 & Yes & Yes & $\mathrm{W} / \mathrm{T}$ & 0 & NA, DN \\
\hline P21 & $\mathrm{F}$ & 77 & Cardiac insufficiency & 20 & Yes & Yes & S/A & 0 & NA, DN \\
\hline P22 & $\mathrm{F}$ & 86 & Fractured thigh bone & 17 & No & No & $\mathrm{M} / \mathrm{T}$ & 2 & NA, OT \\
\hline P23 & M & 89 & $\begin{array}{l}\text { Fractured hip prostate } \\
\text { cancer }\end{array}$ & 35 & Yes & Yes & $\mathrm{M} / \mathrm{T}$ & 3 & NA, OT \\
\hline P24 & $\mathrm{F}$ & 78 & $\mathrm{COL}$, heart disease & 16 & Yes & No & $\mathrm{M} / \mathrm{T}$ & 1 & NA, DN \\
\hline P25 & $\mathrm{F}$ & 85 & Pain, shoulder luxation & $7 ?$ & Yes & Yes & $\mathrm{M} / \mathrm{T}$ & 1 & $\mathrm{NA}+\mathrm{DN}$ \\
\hline P26 & $\mathrm{M}$ & 93 & Fall, leg problem, pain & 13 & Yes & Yes & S/A & 0 & $\mathrm{NA}+\mathrm{DN}+\mathrm{N}$ \\
\hline P27 & M & 88 & $\begin{array}{l}\text { Fractured arm, breathing } \\
\text { problems }\end{array}$ & 19 & Yes & Yes & W/A & 2 & $\mathrm{NA}+\mathrm{DN}$ \\
\hline
\end{tabular}

M, male; F, female, NA, Needs assessor/social worker; DN, District nurse; OT, Occupational therapist; WN, Ward nurse.

${ }^{a}$ Median age of older participants 81 years.

${ }^{b}$ Median stay at the hospital 13 days.

'Social status: S, single; M, married; W, widow. Living conditions: T, together with someone; A, living alone.

transcription of the audio recordings of the discharge planning meetings. Then, the video recordings were analysed together with the transcribed text to clarify parts that were difficult to hear on the audio recordings, such as who said what when there was overlapping conversation or when it was difficult to hear something. This process was intended to enhance the trustworthiness of the data.

Subsequently, all the transcripts were read through to obtain an understanding of the whole. Then the first author reviewed the transcripts and identified condensed meaning units, which consisted of significant text that captured various key statements and thoughts in relation to the study aim. The older person was usually asked at the outset of the discharge care planning meeting for their thoughts and concerns about their needs after discharge. Concerns were interpreted in the analysis as issues, considerations, worries, anxieties and fears that an older person conveyed in the discharge meeting about their postdischarge care and everyday life.

In the next stage, the researchers reviewed the abbreviated text sections several times. During this process, the condensed meaning units were merged into several codes. 
The codes were then combined into subcategories based on similarity of the concerns expressed by the patients in the discharge meetings. The subcategories were merged under three categories based on their characteristics. The categories were cross-examined to ascertain that they were defined to be as homogeneous as possible internally and as heterogeneous as possible externally (33). At this stage of the analysis, one overarching theme emerged.

The categories and the theme were discussed thoroughly and validated by the authors. The discussions continued until no inconsistencies existed and a shared understanding was reached to prevent researcher bias and strengthen the internal validity. Quotations were identified to report the findings and illustrate the content. The selected quotations were then translated from Swedish to English. The use of ... signifies that part of a quote was excluded because it was unimportant or irrelevant to the understanding of the quote.

\section{Ethical considerations}

The study was approved by the Regional Ethical Review Board in Linköping, Sweden (Dnr M87-05). The participants were given written and oral information stating that participation was voluntary, that their identity would be kept confidential and that they were free to withdraw from the study at any time without explanation. The first author (FGJ) obtained oral and written consent from the older patients and oral consent from relatives and professional participants prior to their participation in the discharge meetings. One older patient and three relatives declined participation. The participants also decided on whether to give the researcher permission to videotape, audiotape or merely participate as an observer to take field notes during the meeting. All names used in the quotations were changed to maintain confidentiality.

\section{Findings}

Analysis of the data revealed three categories of concerns that the older persons had about how to manage everyday life after discharge: obtaining a secure life situation; need of continuous care and support; influencing and regaining independence. Each category consisted of three subcategories (Table 2). An overarching theme emerged from the analysis: Being in a life transition. This theme reflected the older peoples' vulnerable position.

\section{Category: Obtaining a secure life situation}

The older persons expressed concerns about how to handle their new life situation and talked about their thoughts on what support or changes might be needed to make them feel confident and secure enough to cope after leaving the hospital.

Being transferred to home or a homely environment. The patients talked about how they could best make their everyday life safe and secure after discharge. The issue of feeling secure was closely associated with where they would be discharged to and what their immediate future would be. Those who believed they would be able to manage on their own, or with care and support organised in their home, stated that their primary desire was to go back home. 'Yes, that is what I would like. Though it is fine to be here, one is longing to be back home again' (woman, aged 86 years). Those with more extensive care needs were more ambivalent about whether they could manage life at home. They pondered whether they would be able to fulfil their security needs by asking for a short stay at a nursing home before returning home. However, their desire was to get back home or to a setting somewhere as close to home as possible. 'Yes maybe that will work, the Lingonberry nursing home is situated near to where I was born. That I could accept. It would be very good, but there are two alternatives for me: Lingonberry or Sveadal. And my desire is to go to Sveadal [a nursing home close to his home]' (man, aged 93 years). Previous experience of environments under consideration seemed to provide a certain sense of security. Many of the patients had lived in the same area throughout their adult life. They also expressed a desire for familiar surroundings, such as an institution they might have visited to see a friend or a family member.

Adjustment to the environment. Many patients voiced concerns about the physical environment and how adjustments could be made so that they could manage everyday life. One

Table 2 Subcategories, categories and theme revealed during the analysis

Overarching theme: Being in a life transition

Category: Obtaining a secure life situation Category: Need of continuous care and support

Subcategory

Back to home or a homely environment

Adjustment to the environment

Financial matters
Subcategory

Need of support with tasks related to daily living

Need of support with round-the-clock care

Concerns about support needed to relieve family members
Category: Influencing and regaining independence

Subcategory

To be seen as a credible participant in care and care planning

To be treated with respect

To be as independent as possible 
man recognised the need to move because he lived in an apartment on the second floor without an elevator. Others were concerned about being dependent on technology or aids. 'Will it take time to get the aids that I need? The most urgent is the heightening aid for the toilet, then I will manage' (woman, aged 74 years). The need for environmental adjustments was different for people who lived with a partner. They had concerns about how to balance their own needs with those of their partner. 'Yes bathing, in the bathtub I will never do again. (...) but there are two of us and one loves bathing. So we will not take it away. I will try to sit on that bath board to shower' (woman, aged 85 years).

Financial matters. Concerns were expressed about the financial situation. Some older people were afraid of having to depend on support or use facilities they believed they could not afford. Individuals living alone who might benefit from services did not think they could afford such support. 'No, I can't afford things. Myself and my friends who have had the home help service, they can't afford it either and they have also declined it' (woman, aged 84 years). Some of the participants expressed concern about the difficulties older people have regarding paying for services. 'The Home Help service has been good, everything except the fees for cleaning. And the same for the security alarm, that is also much too expensive. Personally I think that the municipality ought to supply all older people without any expenses' (man, aged 70 years).

\section{Category: Need of continuous care and support}

In the discharge meetings, the patients gave their views on what care context they preferred after discharge. They then expressed their concerns about what kind of care and support they would need. Some talked about their need for support with various everyday life activities at home; others believed they would be in need of rehabilitation or round-the-clock care. They also voiced concerns about the needs of their family members.

Needs of support with tasks related to daily living. The patients talked about various needs for support to manage everyday living, including showering, toilet visits, cleaning, washing, doing the dishes, laundering, cooking, transport and obtaining medication from the pharmacy. 'I can tell you immediately that I can't do the cleaning or washing ... because I can't do it sitting in the wheelchair and my hands are occupied when walking with those crutches' (woman, aged 69 years).

Concerns about support needed to relieve family members. Some patients had concerns regarding the burden that they might become to their family members: 'When I was healthy everything worked well, everything that I have said now. But then what I have is great, because I have my friend but I can't put this all on her shoulders' (woman, aged 74 years). Some older people wanted services that would also relieve their partners. 'We are in need of help. We're 85 years old, both of us. And we cannot overload my husband here, so that he becomes ill, so what should I do?' (woman, aged 85 years).

Being discharged home increased the older person's access to their partner or other family members, which many felt was of great importance when deciding where to go. When the patients were dependent on support from family members, they wanted to make things as easy as possible for them. Other concerns were about their family members' ability to visit them. Some patients wanted to avoid institutional care if it was inconvenient to their family member. In other cases, they realised that their family members were psychologically distressed due to their role as carer and asked for support to relieve them.

Need of support with round-the-clock care. Patients who perceived they would have health problems or demanding needs for psychosocial support postdischarge expressed a strong desire to be discharged to a short-stay unit in order to have staff supervision both day and night. 'I don't want to be lying on the floor [at home]. I don't think that suits me, yes I am worried. I tell you how it actually is, I'm afraid to get a stroke. ... and then if I'm in need of help then I can call on the staff if I don't feel well' (man, aged 93 years). They addressed their present health status and expressed their expectations for life after discharge. Some individuals asked for professional support with their rehabilitation and wanted to be discharged to a rehabilitation unit. 'I can easily train myself too, but I want to have help so that I do it the right way. It is easy to get it wrong' (woman, aged 74 years).

\section{Category: Influencing and regaining independence}

Most patients clearly expressed that they expected to be treated with respect during discharge planning and they wanted to be involved in the decision-making process about their care. As far as possible, they wanted to organise their day-to-day life in such a way that it supported their independence. They raised objections when case managers or relatives wanted to make plans for them that they did not find appropriate, particularly when they perceived the suggestions intruded on their personal space. The patients expressed that they would prefer not to use Home help or technical aid if it was not absolutely necessary and they wanted to influence the level of service and care. They often wanted to start with a small amount of support and then gradually increase it if they found it necessary. 'I'm a little afraid to commit to things that are unnecessary. But we could start with a little help. I have thought about the way that I would rather work, slowly and taking it step by step. That way I can train my skills' (woman, aged 91 years). 
To be seen as a credible participant in care and care planning. The patients expressed their opinions and wanted to be listened to with regard to how their care should be planned. They reasoned about how care and support could be best organised from their point of view. When asked about her need for support when taking a shower, one woman said: 'Yes, I do absolutely. Yes I can take it every other day if it's what they [home service] think but I think it's troublesome and I'd rather not stretch it longer' (woman, aged 85 years). They also wanted to be seen to be capable of making their own decisions. 'But I thought it went pretty well... so far I'm in control; I can decide how I want it' (man, aged 90 years).

Continuity and competence of care were important aspects of how their care should be organised. 'If they can't grasp what to use things for then you might as well do it yourself. One girl came and she could not empty the vacuum cleaner bag. But I showed her' (man, aged 90 years). Individualised care was often requested. 'Can I have smaller portions, then I can take meals on wheels every day. Maybe I could order a half portion. I don't have any appetite' (woman, aged 88 years).

To be treated with respect. There were concerns about how patients wished to be treated. Many claimed their right to be treated with respect. 'You know my wishes, and still I am clear headed, I know my wants. You should respect them. And on a day when I do not remember or get sick, then the case is clear. I am 93' (man, aged 93 years).

To be as independent as possible. Patients had concerns about getting back to a normal life. Some talked about accepting help or services as a means of retaining independence and ensuring that they could go on living in their home. 'But as long as we can make it work, we think it is the best. And if we can't manage in the house anymore..., we can get help with gardening and cleaning and so on. It is better than going away to a place where you might not feel comfortable' (woman, aged 85 years). Being in charge of one's own transportation was another way to remain independent. 'And I'll have another car ... Yes, with the car arranged, then everything else will be settled' (man, aged 84 years). One man said that he claimed to have his own needs, but that they were not necessarily the ones that his relatives proposed. 'I don't know if it's necessary. What good would it do? It's my sister who says so, because she has it. She wants me to have it like she has it' (man, aged 93 years).

\section{Overarching theme: Being in a life transition}

The overarching theme of being in a life transition emerged in the analysis as an abstraction of our findings; the theme summarises the three categories described previously. The patients expressed feelings about being in an uncertain situation. They believed it was difficult to determine what sort of help they might need and expressed worries about of where they should go after discharge. 'It's a question of how will I feel when back at home. It is hard to tell when I'm still here at the hospital' (woman, aged 79 years). Some believed the decision about care needs was problematic because of their reduced health status. Others thought their health status would improve, which also caused problems because they did not know what support or aid they would need later on.

Finally, patients reflected on what this transition could mean to them from a broader life perspective. They had thoughts about what changes might be needed for themselves and their family members. However, they could only talk about their wishes with just a small chance of making decisions on their own. 'Yes, it's a lot to think about when lying awake at night. Will I manage to get back home? Maybe it'll work. Maybe it would be better if I went to a nursing home? We would have to sell our house first, and we have not considered that' (woman, aged 85 years).

\section{Discussion}

This study explored older people's concerns about their needs as expressed in discharge planning meetings. They had concerns about various needs related to practical day-to-day issues, but they also gave voice to more existential issues. Concerns about being in a life transition emerged as an overarching theme. Transition has been defined as the way people respond to change over time and what they do when they need to adapt to new situations or circumstances in order to incorporate the changes into their lives (34). Many of the participants in our study felt that their situation was awkward, with uncertainty about many issues, including where they would go after discharge. Some of them had previous experience of care and support, whereas others had no such experience. However, this variation did not seem to influence their ambivalence. The participants said that it was difficult to assess what their needs were because they found it hard to assess their own current capacity. All were troubled about their need for care and services and they strived to stay independent with as little public support as possible. Our findings concerning this ambivalence are consistent with other researches dealing with needs assessment by municipal care managers of older people who can no longer manage on their own (12, 35). Our findings are also of clinical importance though professionals need to be sensitive to what level of care and support the patient demands and thereby take in to consideration that older person often initially prefer less 
than more. When the older person is not familiar with the old-age care and has little or no experience of being cared for they need some time to adapt to this new life situation.

Several studies have shown that older people and their relatives lack information about their care and are unprepared when they take part in discharge planning $(9,14,36)$. This reduces their potential to influence the decisions regarding their care, enhancing their vulnerable position (24). Studies have shown that patients experience a less uncertain transition from hospital and have fewer concerns when going home when care managers or nurses who have worked with different types of information interventions to prepare service users for their postdischarge situation are involved (4, 25).

The older persons in our study wanted to achieve a secure life situation. This finding is in accordance with the results of a Swedish study of older people receiving care in a municipality where the participants defined good care as receiving safe and secure care (10). In our study, the participants asked to be discharged to a place that they felt confident with. To some, this meant being discharged to their own home with all the services they might need. In Sweden, 'ageing in place' is the main policy for care and is used by case managers to ensure that municipal resources are used as efficiently as possible. Ageing in place refers to being able to remain in one's current home when faced with increasing needs for support because of life changes (37). According to a study by Wiles et al. (38), older people interpret the meaning of the concept as something more than the home, describing it in terms of functional, symbolic and emotional attachments of the home, neighbourhood and community, which provide a sense of security and familiarity. Ageing in place can be understood in terms of ecological models of ageing (39). According to such models, a person's functioning is the result of their biological, psychological and social resources, their environmental characteristics and the fit between the individuals and their environments. When demands from social and physical environments overwhelm an individual's resources the older person is less likely to age in place (40). The ecological model might be helpful to understand why ageing in place in some cases cannot fulfil the older person's needs anymore. Older participants in this study viewed ageing in place as more than just their home. This was especially obvious for those participants who said that home was not the optimal place when they felt in need of round-the-clock care but still needed familiarity to feel secure. We also found that older people took their family into account when they considered postdischarge care options. They did not want their care to inconvenience a family member and asked for arrangements that were as convenient as possible for their family. Ecological models typically focus on personenvironment processes, and it is important to account for family members as an integral aspect of the social environment.

Older people are not a homogeneous group. In a study of 335 older patients, Coffey and McCarthy (41) showed differences between age groups in their perception of readiness to discharge; the older elderly had the lowest perception of readiness. The older elderly also used more informal and formal support after discharge.

Another interesting finding in our study is that some older people said that they could not afford services. In Sweden, health care and social services are publically funded and individuals who are short of means can apply for reduced fees or no fees at all. The care managers provided little or no information about this. We do not know whether the participants declined services because of real poverty or whether they had other priorities than spending their resources on services.

There has been a great deal of research investigation into various aspects of the concept of needs since this is a crucial concept in health care and social services. Previous research about needs has been conducted across a wide range of disciplines (social care, ethics, economics and health care). There is an ongoing debate on how to distinguish between needs, wants and demands. Many of these studies conclude that there is considerable confusion regarding the meaning of these concepts (42-44). Our study did not explore what the participants defined as their needs, instead focusing on their concerns as expressed in the discharge meetings. This is the main arena where they can present their demands and influence decisions about their postdischarge care.

The patients in our study emphasised that they wanted to influence their care planning and be treated with respect. Our findings are consistent with Rise et al. (45), who concluded that mutual respect between providers and service users is of fundamental importance for patients as participants in care and care planning. Similar findings were reported by From et al. (10) in a study of how older people define and experience good care. They observed that older people want to be invited to a mutual relationship. When caregivers provided care in accordance with the older person's wishes and needs, this was experienced as respect for them as a person. In a study of 254 older people aged $80+$ years, Foss and Hofoss (46) stressed that despite their age, the patients did express a clear preference for participation in discharge planning. Many of the participants in our study applied their will to participate in their care and care planning in a subtle and discreet way. If professionals and older people do not see patient participation in the same way, there is a risk that the patients' wishes are ignored or overlooked $(47,48)$. 


\section{Methodological considerations}

This study has some methodological shortcomings that must be considered when interpreting the results. All older participants in the study had a Swedish ethnic background, which may have had an impact on the concerns raised by them. Thus, the results should not be overgeneralised. Collecting more data could theoretically have enhanced the trustworthiness of the results, but sampling to the point of redundancy is often an unattainable ideal (31).

This study was limited to the older patient's concerns about their everyday life after discharge as expressed in discharge meetings. The data were collected by observing real conversations. The study did not account for dialogue with professionals or family members, which may have had an influence on what the older participants brought up in the conversations. However, the findings are of interest to explore what issues are talked about.

We have explored and presented in our findings on what issues the older people express in these meetings which indirectly give us information about what issues or concerns they do not spontaneously talk about. This is important knowledge to staff so they could develop their communication and not neglect to initiate issues that can be of importance for the postdischarge care. In a review of patient participation, few studies made attempts to observe what occurs in practice, and other data collection methods such as questionnaires or interviews are more commonly used (49). Based on this knowledge, we plan to accomplish a discourse analysis, based on the 22 videotaped discharge planning meetings used in this study. Our interest is to further explore the communication patients have with professionals and family members to elucidate how concerns about postdischarge needs are negotiated.

It is difficult to determine whether the participation of the researcher and the videotaping procedure affected the conversations at the discharge meetings. All participants were informed about the procedure. The video recordings strengthened data reliability by transcribing what was said during the meetings (50). In multiparty meetings, conversations tend to overlap and the older people's voices were not always the strongest. It was necessary to go back and forth in the material to ensure correct understanding of what was really said and by whom. The video recordings made it possible to distinguish the voices.

\section{Conclusions}

The results show that the older people want to have an influence on their care when they participate in discharge planning and they have concerns about what care context they will be discharged to. They strive to regain independence and express their concerns about how to obtain a secure postdischarge life situation through support and care organised to fit their individual needs. Overall, their concerns can be viewed in terms of being in a life transition, reflecting their vulnerable and ambivalent situation. This knowledge is important for social workers and healthcare providers involved in planning and optimising individualised care and services for older people.

\section{Acknowledgements}

Our gratitude goes to the participants who shared their life world with us. We also would like to thank our colleagues, especially Elisabet Cedersund, Sofia Kjellström, Gerdt Sundström, Magnus Jegermalm, Berith Hedberg and Bo Malmberg for valuable comments on previous drafts on the manuscript.

\section{Author contributions}

Felicia Gabrielsson-Järhult designed the study and collected the data. Both authors analysed the data and prepared the manuscript.

\section{Ethical approval}

The study was approved by the Regional Ethical Review Board in Linköping, Sweden (Dnr M87-05).

\section{Funding}

The work was funded from the Institute of Gerontology, School of Health Sciences at Jönköping University. No conflict of interest has been declared by the author(s).

\section{References}

1 Watts R, Gardner H. Nurses' perceptions of discharge planning. Nurs Health Sci 2005; 7: 175-83.

2 National Board of Health and Welfare. SOSFS 2005:27 (M och S). Föreskrifter; Samverkan vid in- och utskrivning av patienter i slutenvård
[Regulations; cooperation at admission and discharge of hospital patients]. Socialstyrelsens författningssamling, Stockholm (in Swedish).

3 Janlöv A-C, Hallberg IR, Petersson K. The experience of older people of entering into the phase of asking for public home help - a qualitative study. Int J Soc Welf 2005; 14: 32636.

4 Rydeman I, Törnqvist L. The patient's vulnerability, dependency and exposed situation in the discharge process: experiences of district nurses, geriatric nurses and social workers. J Clin Nurs 2006; 15: 1299307. 
5 Rydeman I, Törnqvist L. Getting prepared for life at home in the discharge process - from the perspective of the older persons and their relatives. Int $J$ Older People Nurs 2010; 5: 254-64.

6 Denson LA, Winefield HR, Beilby JJ. Discharge planning for long-term care needs: the value and priorities of older people, their younger relatives and health professionals. Scand J Caring Sci 2013; 27: 3-12.

7 Preyde M, Chapman T. Psychosocial profile of elderly patients discharged from a community hospital. Soc Work Health Care 2007; 45: 77-95.

8 Berglund H, Dúner A, Blomberg S, Kjellgren K. Care planning at home: a way to increase the influence of older people? Int J Integr Care 2012; 12: $1-12$

9 Ekdahl A, Larsson A, Friedrichsen M. "They do what they think is best for me". Frail elderly patients' preferences for participation in their care during hospitalization. Patient Educ Couns 2010; 80: 233-40.

10 From I, Johansson I, Athlin E. The meaning of good and bad care in the community care: older people's lived experiences. Int $\mathrm{J}$ Older People Nurs 2009; 4: 156-65.

11 Efraimsson E, Sandman PO, Hýden LC, Holritz Rasmussen B. How to get one's voice heard: the problems of the discharge planning conference. $J$ Adv Nurs 2006; 53: 646-55.

12 Janlöv A-C, Hallberg IR, Petersson K. Older persons' experience of being assessed for and receiving public home help: do they have any influence over it? Health Soc Care Community 2006; 14: 26-36.

13 Coffey A. Discharging older people from hospital to home: what do we know? Int J Older People Nurs 2006; 1: $141-50$

14 Bull M, Lori L. Strategies used by chronically ill older women and their caregiving daughters in managing post-hospital care. J Adv Nurs 1997; 25: 541-7.

15 Berendsen AJ, Majella de Jong G, Meyboom-de Jong B, Dekker JH, Shuling J. Transition of care: experiences and preferences of patients across primary/secondary interface a qualitative study. BMC Health Serv Res 2009; 9: 62 .
16 Dossa A, Bokhour B, Hoenig H. Care transitions from the hospital to home for patients with mobility impairments: patient and family caregiver experiences. Rehabil Nurs 2012; 37: 277-85.

17 Auslander GK, Soskolne V, Ben-Shadar I, Kaplan G. Discharge planning in acute care hospitals in Israel: services planned and levels of implementation and adequacy. Health Soc Work 2008; 33: 178-88.

18 Holland DE, Knafl GJ, Bowles KH. Targeting hospitalised patients for early discharge planning intervention. J Clin Nurs 2013; 22: 2696-703.

19 Shepard S, Lannin NA, Clemson LM, McCluskey A, Cameron ID, Barras SL. Discharge planning from hospital to home. Cochrane Database Syst Rev 2013: CD000313.

20 Driscoll A. Managing post-discharge care at home: an analysis of patients' and their carers' perceptions of information received during their stay in hospital. J Adv Nurs 2000; 31: 116573.

21 Procter S, Wilcockson J, Pearson P, Allgar V. Going home from hospital: the carer/patient dyad. J Adv Nurs 2001; 35: 206-17.

22 Foss C, Askautrud M. Measuring the participation of elderly patients in the discharge process: a critical review of existing instruments. Scand J Nurs Sci 2010; 24: 46-55.

23 Kennedy CR, Chandran D, Sergeant J, Koenig TL. Hospital to community transitions for adults: discharge planners and community service providers' perspectives. Soc Work Health Care 2014; 53: 311-29.

24 Hedberg B, Johansson M, Cederborg AC. Communicating stroke survivors health and further needs for support in care-planning meetings. $J$ Clin Nurs 2008; 17: 1481-91.

25 Fagermoen MS, Hamilton G. Patient information at discharge - a study of a combined approach. Patient Educ Couns 2006; 63: 169-76.

26 Efraimssson E. Vårdplaneringsmötet. En studie av det institutionella samtalet mellan äldre kvinnor, närstående och vårdare [The discharge care planning meeting. A study of the institutional conversation between older women, relatives and professionals]. Dissertation no
967. Umeå University, Umeå, Sweden. 2005 (in Swedish).

27 Rydeman I. Discharged from hospital and in need of home care nursing. Experience of older persons, their relatives and care professionals. Dissertation 13:4. Karolinska Institutet, Stockholm, Sweden. 2013.

28 Health and Medical Services Act. SFS 1982:763. [Hälso och sjukvårdslagen].

29 Local Government Act. SFS 1991:900. [Kommunallagen].

30 Social Services Act. SFS 2001:453. [Socialtjänstlagen].

31 Patton MQ. Qualitative Research $\theta$ Evaluation Methods, 3rd edn. 2002, Sage Publications, Thousand Oaks, CA.

32 Graneheim UH, Lundman B. Qualitative content analysis in nursing research: concepts procedures and measures to achieve trustworthiness. Nurse Educ Today 2004; 24: 105-12.

33 Krippendorff K. Content Analysis. An Introduction to its Methodology, 2nd edn. 2004, Sage Publications, Thousand Oaks, CA.

34 Kralik D, Visentin K, van Loon A. Transition: a literature review. $J A d v$ Nurs 2006; 55: 320-9.

35 Dunér A, Nordström M. Intentions and strategies among elderly people: coping in everyday life. J Aging Stud 2005; 19: 367-80.

36 Tierney A, Closs J, Hunter H, MacMillan M. Experiences of elderly patients concerning discharge from hospital. J Clin Nurs 1993; 2: 179-85.

37 Greenfield E. Using ecological frameworks to advance a field of research, practice and policy on aging-in-place initiatives. The Gerontologist 2012; 52: $1-12$.

38 Wiles J, Leibling A, Guberman N, Reeve J, Allen R. The meaning of "Aging in Place" to older people. Gerontologist 2012; 52: 357-66.

39 Lawton MP, Nahemow L. Ecology and the aging process. In Psychology of Adult Development and Aging (Eisdorfer C, Lawton MP eds), 1973, American Psychological Association, Washington, DC, 619-74.

40 Lawton MP, Weisman GD, Sloane P, Calkins M. Assessing environments for older people with chronic illness. J Mental Health Aging 1997; 3: 83100.

41 Coffey A, McCarthy G. Older people's perception of their readiness for 
discharge and postdischarge use of community support and service. Int $J$ Older People Nurs 2013; 8: 104-15.

42 Doyal L, Gough I. Human needs and socialist welfare. Praxis Int 1986; 6: 43-69 (based on a previous article: Doyal L, Gough I. A theory of human needs. Critical Social Policy 1984; 4: 6-38).

43 James M. Towards an integrated needs and outcome framework. Health Policy 1999; 46: 165-77.

44 Asadi-Lari M, Packham C, Gray D. Need for redefining needs. Health Qual Life Outcomes 2003; 1: 34.
45 Rise M, Solbjor M, Lara M, Westerlund $\mathrm{H}$, Grimstad H, Steinsbekk A. Same description, different values. How service users and providers define patient and public involvement in health care. Health Expect 2011; 16: 266-76.

46 Foss C, Hofoss D. Elderly persons' experience of participation in hospital discharge process. Patient Educ Couns 2011; 85: 68-73.

47 Penney W, Wellard S. Hearing what older consumers say about participation in their care. Int $J$ Nurs Pract 2007; 13: 61-68.
48 Foss C. Elders and patient participation revisited - a discourse analytic approach to older people' reflections on patient participation. J Clin Nurs 2011; 20: 2014-22.

49 Cahill J. Patient participation - a review of the literature. J Clin Nurs 1998; 7: 119-28.

50 Silverman D. Interpreting Qualitative Data, 3rd edn. 2006, Sage Publication, London. 